\title{
Research Square \\ Home Care Practices of Cancer Caregivers and the Effect of Perceived Social Support on Care Burden
}

\section{Tuba Ulgen}

Dokuz Eylul University Faculty of Medicine: Dokuz Eylul Universitesi Tip Fakultesi

Özlem Uğur ( $\nabla$ ozlem.ugur@deu.edu.tr)

Dokuz Eylul Universitesi

\section{Research Article}

Keywords: Home Care Practices, Cancer Caregivers, Social Support, Care Burden, morbidity and mortality worldwide

Posted Date: November 9th, 2021

DOI: https://doi.org/10.21203/rs.3.rs-1055812/v1

License: (c) (i) This work is licensed under a Creative Commons Attribution 4.0 International License. Read Full License 


\section{Abstract}

Purpose: Caregivers have to manage tasks at home such as providing management of the patient's follow-up. Social support is known to have protective effects, especially for family members and caregivers for cancer patients. The aim of this study is to investigate the effect of care on home care and perceived social support on cancer burden.

Methods: A descriptive and cross-sectional study. This study was conducted in the Chemotherapy Day Treatment Unit of a University Research and Application Hospital. a 222 patients were included in the study. In this study, Caregiver and Patient Identification Form, Caregiver's Home Care Practices Questionnaire Form, Zarit Caregiver Burden Scale, Perceived Multidimensional Social Support Scale, Karnofsky Performance Scales were used. The data of the study were collected by face-to-face interviews conducted with the caregivers.

Results: In our research the social support level was found to be moderately adequate and had a mild maintenance burden. In our study, when the relationship between the multidimensional perceived social support scale scores and the Zarit care load scale scores is examined it was found that there was a significant relation between the perceived social support total scores of caregivers and the care burden scores in a weak and negative way $(p<.01)$.

Conclusion: It has been determined that the caregivers of cancer patients have taken care of their home care practices and the perceived lack of social support.

\section{Introduction}

Cancer, which is one of the major health problems today, is a significant cause of morbidity and mortality worldwide [1]. According to the data provided by GLOBOCAN; In 2018, the total number of new cancer cases in the world was determined to be 18.1 million and 9.5 million cancer-related deaths were reported. The total incidence of cancer in Turkey is 210.2 per a hundred thousand population and 163.417 new cases of cancer were diagnosed [2]. Due to the great advances in cancer treatment, outpatient treatment has acquired more significance. This shortens the length of hospital stay and causes family members to take over the management of their patients at home and assume increased care responsibilities [3-5]. Caregivers have to manage tasks at home such as providing management of the patient's follow-up and symptoms for an average of 8 hours per day as well as helping to carry out work related to the house and children. It is reported that the care burden is high regarding caregivers who are not adequately prepared for the management of home care, who have to deal with increasingly complex conditions of patient care and who lack adequate support while giving care [6-8]. In this process, caregivers may experience problems such as loneliness, social isolation and deterioration in interpersonal relationships because of staying away from family, friends or social activities. They may have difficulty in dealing with daily stressors and their overall quality of life may deteriorate [6-7, 9]. Social support is known to have protective effects, especially for family members and caregivers for cancer patients [7,10-11]. The aim of 
this study is to examine the effect of home care practices and perceived social support of cancer caregivers on care burden.

\section{Methods}

Study design: This is a descriptive and cross-sectional study. This study was conducted in the Chemotherapy Day Treatment Unit of Dokuz Eylül University Research and Application Hospital between September 2017 and May 2018.

Participants: In the study, the unknown population sampling method was used and the caregivers of 222 patients who applied to the treatment unit were included. The research sample consisted of 222 caregivers who were aged 18 or above, speakers of Turkish, ble to communicate with the researcher who is 18 years of age or older, who can speak Turkish, had an oncologic or hematologic malignancy, had been caring for their patients for at least 3 months, had been living in the same house with their patients and maintaining care responsibilities, had good cognitive functioning, were open to communication and cooperation with the researchers, and willing to participate in the research [11-12]. As for the exclusion criteria; caregivers of patients who had a Karnofsky performance value of $20 \%$ and below, those providing care in turns and who were not willing to participate were excluded from the scope of the study [7].

\section{Data Collection Tools}

Five data collection tools were used to collect the data of the study.

\section{Patient and Caregiver Identification Form}

2. Caregiver's Home Care Practices Questionnaire

\section{Zarit Burden Interview}

\section{Multidimensional Scale of Perceived Social Support}

\section{Karnofsky Performance Status Scale}

Patient and Caregiver Identification Form; was prepared according to the literature review. The form consists of questions aiming to identify the sociodemographic and health status of the patients and caregivers [12-14].

Caregiver's Home Care Practices Questionnaire; this is a three-part form prepared according to the literature review in order to define the roles of the caregiver regarding the patient's medical, non-medical management and personal care. The form includes questions to determine the care responsibilities of the caregiver such as oral care, catheter care, nutrition and wound dressing in addition to their duties such as the follow-up of medication and treatment of the patient, provision of the prescribed drugs, household chores, shopping, transportation and payment of the bills [12-13, 15]. A Likert-type assessment method 
was used for the evaluation of the items in the questionnaire ( 0 No, 1 Sometimes and 2 Yes). The higher scores obtained from the survey indicate a higher number of home care practices given to the patient while the lowers scores indicate a low number of care-oriented practices. In order to determine the scope validity, expert opinions were obtained from 9 people including 5 faculty members, 2 specialist doctors and 2 clinically responsible nurses before using the form in the study. After the feedback, the form was finalized. When the scope validity index of the questionnaire was examined, Cronbach's alpha value was found to be 0.90 for Medical Care Management sub-dimension; 0.83 for Non-Medical Care Management sub-dimension and 0.98 for Provision of Patient Personal Care sub-dimension. Before the study was started, the questionnaire, which obtained good validity scores, was administered to 3 patients to determine its usability. Three patients were excluded from the study.

Zarit Caregiver Burden Scale (ZBI); Zarit was developed by Reever and Bach-Peterson in 1980. The testretest reliability of the Caregiver Burden Scale was found to be very reliable with a coefficient of $0.71-$ 0.60 . It is a scale used to evaluate the stress experienced by caregivers of individuals or the elderly in need of care. The validity and reliability of the Turkish version was conducted by Inci. The Cronbach's alpha value of the scale was found to be 0.95 which was highly reliable [16].

The Multidimensional Scale of Perceived Social Support; The Cronbach's alpha coefficient of the scale, which was developed by Zimet et. al. and revised by Eker et al. in 2001 was found to be $0.80-0.95$. The scale consists of a total of 12 items. The scale is a 7-point Likert-type scale ranging from "very strongly disagree $1,2,3,4,5,6,7$ to very strongly agree". The scale has three sub-dimensions relating to the source of the social support; namely family, friend and significant other, each consisting of 4 items. In the scale, items $3,4,8,11$ measure family support; items $6,7,9,12$ measure friend support and items $1,2,5,10$ measure the support from the significant other. The lowest score that can be obtained from the sub-dimensions is 4 while the highest is 28 . The lowest score that can be obtained from the total scale is 12 while the highest is 84 . The internal consistency coefficient varies between 0.80 and 0.95 [17].

Karnofsky Performance Status Scale; which was defined by Dr. Joseph H. Burchenal and Dr. David A Karnofsky in 1949, is used to evaluate the general well-being of cancer patients in oncology and other fields [18].

\section{Collecting Research Data}

The data of the study were collected by face-to-face interviews conducted with the caregivers of cancer patients receiving treatment in the Chemotherapy Day Treatment Unit of Dokuz Eylül University Research and Application Hospital. In the process of data collection; the researcher identified the individuals who met the sampling criteria, explained the purpose of the research and interviewed the caregivers who agreed to participate in the study.

\section{Data Analysis}

For the analysis of data, descriptive statistics (number, percentage, mean and standard deviation); oneway analysis of variance for the comparison of the care burden mean score according to the descriptive 
characteristics of caregivers and Kruskal Wallis analysis were used according to occupation, economic status and family type variables. Pearson correlation analysis was used to evaluate the relationship between the Multidimensional Scale of Perceived Social Support, the home care practices scores of the caregivers of cancer patients, the performance scores of their patients and the careburden scores. The relationship between caregivers and independent variables that may have an impact on care burden score was evaluated by multiple regression (backward elimination) analysis. Significance level was accepted to be $\mathrm{p}<.05$.

\section{Results}

Of the caregivers included in the study (n: 222), it was found that $47.3 \%$ were in the $40-61$ age group, $64.4 \%$ were women, $73 \%$ were married, $37.8 \%$ were graduates of higher education, $31.5 \%$ were housewives, $68.9 \%$ did not have a job, $73.9 \%$ had moderate economic status and $86.5 \%$ had social security. It was found that $69.8 \%$ of the caregivers had nuclear families, $72.5 \%$ had children and $60.4 \%$ were not directly responsible for child care. It was found that $77.9 \%$ of the caregivers did not have any chronic diseases, $40.1 \%$ cared for their spouses, $33.8 \%$ provided care exceeding 19 hours per day, $55 \%$ provided care for their patients for 3 to 10 months, 53.6\% received help for caring for their patients, $51.4 \%$ had patients with a diagnostic duration of 3 to10 months, $60.4 \%$ had patients with metastasis, and $23 \%$ of the patients had a performance status of $80 \%$.

It was determined that the caregivers conducted the follow-up of their patients' medical problems, arranged their nutrition, medication and appointments, helped with the household chores (shopping, childcare, payment of bills), gave their patients emotional support, helped with their exercises and provided massage. However, it was found that the patients in the sample group were able to perform their own personal care easily because of their high performance status (Table 1).

Table 1. Caregiver's Home Care Practices 


\begin{tabular}{|c|c|c|c|}
\hline Home Care Practices & Yes & Sometimes & No \\
\hline Medical Care Management & $N \%$ & $N \%$ & $N \%$ \\
\hline Follow-up of medical problems & 18181.5 & 229.9 & 198.6 \\
\hline Follow-up of medication & 19788.7 & 167.2 & 94.1 \\
\hline Arranging appointments & 20491.9 & 83.6 & 104.5 \\
\hline Provision of prescribed drugs and medical equipment & 20090.1 & 156.8 & 73.2 \\
\hline Preparation of special diet requirements & 16976.1 & 2410.8 & 2913.1 \\
\hline \multicolumn{4}{|l|}{ Non-Medical Care Management } \\
\hline $\begin{array}{l}\text { Managing household chores during the care process } \\
\text { (cleaning, repair) }\end{array}$ & 16373.4 & 3817.1 & 219.5 \\
\hline $\begin{array}{l}\text { Helping with duties related with children during the care } \\
\text { process (transportation to school, parent meetings etc.) }\end{array}$ & 8739.2 & 167.2 & $\begin{array}{l}119 \\
53.6\end{array}$ \\
\hline $\begin{array}{l}\text { Doing necessary shopping (clothing, nutrition, special } \\
\text { requirements etc.) }\end{array}$ & 18683.8 & 2712.2 & 94.1 \\
\hline $\begin{array}{l}\text { Taking responsibility in the transportation of the patient to } \\
\text { hospital }\end{array}$ & 20893.7 & 94.1 & 52.3 \\
\hline $\begin{array}{l}\text { Paying the bills of the patient (electricity, water, telephone, } \\
\text { custom invoices, house rents etc.) }\end{array}$ & 13661.3 & 2310.4 & 6328.4 \\
\hline Having another job during the care process & 6730.2 & 125.4 & $\begin{array}{l}143 \\
64.4\end{array}$ \\
\hline $\begin{array}{l}\text { Financial impact on the care process (loss of job, decrease in } \\
\text { job continuity, travel or accommodation fees) }\end{array}$ & 13159.0 & 2310.4 & 6830.6 \\
\hline \multicolumn{4}{|l|}{ Provision of Patient Personal Care } \\
\hline Oral care & 8940.1 & 3817.1 & 9542.8 \\
\hline \multicolumn{4}{|l|}{ Assisting with body care (bathing) } \\
\hline Foot care & 9341.9 & 4620.7 & 8337.4 \\
\hline Maintenance of urinary catheter & 3616.2 & 104.5 & $\begin{array}{l}176 \\
79.3\end{array}$ \\
\hline Maintenance of the feeding tube (Feeding, PEG) & 3013.5 & 41.9 & $\begin{array}{l}188 \\
84.7\end{array}$ \\
\hline Supporting the patient emotionally & 19989.6 & 83.7 & 156.8 \\
\hline Performing tube feeding (PEG) & 2310.4 & 20.9 & $\begin{array}{l}197 \\
88.7\end{array}$ \\
\hline Maintenance of colostomy, ileostomy or urostomy & 2410.8 & 52.3 & $\begin{array}{l}193 \\
86.9\end{array}$ \\
\hline
\end{tabular}




\begin{tabular}{|llll|}
\hline Home Care Practices & Yes & Sometimes & No \\
\hline Maintenance of tracheostomy & 188.1 & 41.8 & $\mathbf{2 0 0}$ \\
\hline Assisting the patient while walking or with in-bed exercises & 12355.4 & 4419.8 & 5524.8 \\
\hline Wound or catheter dressing & 8739.2 & 177.7 & 118 \\
\hline & & & 53.2 \\
\hline Injection (insulin, blood thinners, blood-forming drugs, etc.) & 11451.4 & 4319.4 & 6529.3 \\
\hline
\end{tabular}

It was found that while the total score the caregivers obtained from the MSPSS was $61.29 \pm 17.27$; the total score they obtained from the home care practices questionnaire was $28.88 \pm 7.72$, and the total score obtained from the ZBI was $29.11 \pm 14.58$ (Table 2).

Table 2. Caregivers' Descriptive Statistics of the Multidimensional Scale of Perceived Social Support (n: 222) 


\begin{tabular}{|c|c|c|}
\hline Scale and Sub-dimensions & Lowest-Highest & $\mathbf{x} \pm$ SD \\
\hline $\begin{array}{l}\text { Multidimensional Scale of Perceived Social } \\
\text { Support (MSPSS -Total) }\end{array}$ & $14-84$ & $61.29 \pm 17.27$ \\
\hline \multicolumn{3}{|l|}{ MSPSS Sub-Dimensions } \\
\hline Family & $4-28$ & $23.05 \pm 5.96$ \\
\hline Friend & $4-28$ & $20.25 \pm 7.10$ \\
\hline Significant Other & $4-28$ & $18.00 \pm 7.77$ \\
\hline $\begin{array}{l}\text { Caregiver's Home Care Practices Questionnaire } \\
\text { (Total) }\end{array}$ & $10-50$ & $28.88 \pm 7.72$ \\
\hline \multicolumn{3}{|l|}{ Care Sub-Dimensions } \\
\hline Medical Care Management & $4-10$ & $9.00 \pm 1.60$ \\
\hline Non-Medical Care Management & $0-14$ & $9.48 \pm 2.65$ \\
\hline Provision of Patient Personal Care & $0-26$ & $10.41 \pm 5.95$ \\
\hline \multirow{2}{*}{$\begin{array}{l}\text { Zarit Caregiver Burden Scale Total Scores } \\
\text { Classification of Care Burden }\end{array}$} & $0-88$ & $29.11 \pm 14.58$ \\
\hline & $\mathbf{N}$ & $\%$ \\
\hline Little or no burdensteps $\quad(0-20$ points $)$ & 67 & 30.2 \\
\hline Mild to moderate burden ( $21-40$ points) & 114 & 51.4 \\
\hline Moderate to severe burden ( $41-60$ points) & 36 & 16.2 \\
\hline$(61-88$ points $)$ & 5 & 2.3 \\
\hline
\end{tabular}

As seen in Table 3, it was found that there was a weak and negative correlation between the perceived social support total scores and caregiver burden scores of caregivers $(p<.01)$. There was a weak and negative correlation between the MSPSS family and significant other sub-dimension scores and caregiver burden scores; however, the relationship was not significant ( $p>.05)$, while the friend sub-dimension scores indicated a weak, negative but statistically very significant correlation $(p<.01)$. A statistically significant positive but weak correlation was found between Karnofsky performance status scores and caregiver burden scores $(p<.01)$. As the performance scores of the patients decrease, caregivers' burden scores increase. When the relationship between Home Care Practices Questionnaire Scores and ZBI 
scores were examined, a moderately positive, significant correlation was found $(p<.001)$. It was found that there was no significant relationship between the medical and non-medical care management subdimension scores and caregiver burden scores ( $p>$.05). However, a moderately positive and highly significant correlation was found between the provision of patient personal care sub-dimension scores and caregiver burden scores $(p<.001)$. It was found that as the total score of home care practices and the provision of patient personal care sub-dimension scores increased, caregiver burden scores also increased.

Table 3. The Relationship between the Multidimensional Scale of Perceived Social Support, Karnofsky Performance Status Scale, Home Care Practices and Zarit Caregiver Burden Scale Scores of Caregivers (n: 222)

\begin{tabular}{|lll|}
\hline Scale and Sub-dimensions & \multicolumn{2}{l}{ Zarit Caregiver Burden Scale } \\
\hline & $\mathbf{r}$ & $\mathbf{p}$ \\
\hline 1. Multidimensional Scale of Perceived Social Support (Total) & -.18 & .009 \\
\hline MSPSS Sub-Dimensions & & \\
\hline A. Family & -.13 & .051 \\
\hline B. Friend & -.22 & .001 \\
\hline C. Significant Other & -.09 & .208 \\
\hline 2. Karnofsky Performance Status Scale & .19 & .004 \\
\hline 3 Home Care Practices Questionnaire Form & .30 & .000 \\
(Total) & & \\
\hline Sub-Dimensions & & \\
\hline Medical Care Management & .05 & .454 \\
\hline Non-Medical Care Management & .13 & .058 \\
\hline Provision of Patient Personal Care & .32 & .000 \\
\hline
\end{tabular}

A highly significant correlation was found between the diagnostic duration and the duration of care provision ( $\mathrm{r}: .93, \mathrm{p}<.001$, Tolerance value: .128, VIF: 7.811), the MSPSS total scores and the friend subdimension scores (r: .83, p<. 001, Tolerance value: .274, VIF: 3.649) and daily care practices total score and personal care sub-dimension scores (r: .91, p <.001, Tolerance value: .158, VIF: 6.311) according to the multicollinearity statistics. In the study, the effect of the variable of the caregiver having to provide care for persons other than cancer patients on the caregiver burden was found to be marginally significant ( $\mathrm{p}$ : .05 to $.10, .05<\mathrm{p}<.10$ ). The five independent variables explain the variance in caregiver burden score by $20 \%$. 
While the 1-point increase in the personal care sub-dimension scores of the home care practices questionnaire increases the caregiver burden scores by .77 points; 1-point increase in the friend subdimension scores of the MSPSS decreases the caregiver burden scores by -.31 points. The caregiver burden score of caregivers with fragmented family type was 4.46 points higher than those with large and nuclear families; caregivers who were responsible for their patients alone had a burden score which was 4.07 points higher than those who received support; those who provided care for patients with metastases had a burden score which was 4.07 points higher than those who provided care for patients with no metastases; and, caregivers who provided care to someone else in addition to the cancer patient had a burden score which was 3.63 points higher than those who only provided care for their patients.

\section{Discussion}

In this study, it was found that $47.3 \%$ of caregivers were in the $40-61$ age group and $64.4 \%$ were women. In the studies conducted previously, it was also emphasized that the mean age of primary caregivers gradually increased and that the gender was predominantly female [7, 12, 19]. Kaynar \& Vural (2018) reported that women considered providing care as a continuation of their responsibilities. In the study investigating the Turkish family structure conducted by the survey of the Republic of Turkey, Ministry of Family and Social Policies (2011), it is stated that housework is mostly done by women in the household (88\%). According to the overall results of the research regarding the general condition in Turkey, it is stated that the responsibility of providing care to the persons in need in the household is undertaken by wives, mothers and brides respectively [5].

In our study, it was found that $68.9 \%$ of the caregivers did not have a job, $73.9 \%$ had moderate economic status and $37.8 \%$ were graduates of higher education. In the literature, there are studies that are supportive of our findings [7, 11-12]. Our findings are similar to studies [5].

In our study, it was found that the caregivers conducted the follow-up of their patients' medical problems, arranged their nutrition, medication and appointments, helped with the household chores (shopping, childcare, payment of bills), gave their patients emotional support and helped with their exercises throughout the care process (Table 1). Our findings are consistent with the literature [7, 19-20]. When all these are examined, caregiving becomes a very tiring process, and when it is not managed effectively, it affects patient care negatively and presents itself as a burden for caregivers [3, 21]. In our study, it was found that the level of social support perceived by caregivers was sufficient at a moderate level (Table 3 ). When the sub-dimensions were examined, it was determined that the caregivers perceived the support received from family more than the support from friends or significant others. It is thought to be stemming from the fact that spouses, children and other family members support each other in case of an illness according to the traditional Turkish family structure. This finding is in line with those similar [9, 21]. In our study, it was determined that caregivers had a slight burden since $45 \%$ of the patients had $80 \%$ or higher performance status, their diagnostic duration ranged from 3 to 10 months, the majority of the caregivers did not have any chronic diseases or have to take care of another person. In the literature, it is 
stated that the burden scores of the caregivers of patients with high physical competence are better than those with high physical care burden [7].

In the study, it was found that the burden scores of caregivers of cancer patients increased as the total score of home care practices and the provision of patient personal care sub-dimension scores increased (Table 4). Our findings are similar to studies [3, 7]. Caring for cancer patients affects the lives of family members and brings along many difficulties. For this reason, caregivers need to be supported by their families, feel that they are not left alone, receive help regarding finance, information and training as well as social and emotional support. Social support has significant effects on caregivers and increases care burden $[3,7,9]$. It was found that the care burden mean scores of caregivers who did not receive help from others and who were obliged to provide care for another were found to be higher (Sun et al., 2019). This finding is supportive of our study. This may be related with the fact that the sample group's patient population were able to perform their home care activities. Because when the performance status of the patients of the caregivers included in the study is examined, it is seen that $45.1 \%$ of the patients have a performance status of $80 \%$ and above. In our study, a statistically significant difference was found between the groups care burden scores according to the duration of home care and the total duration of care provision to the patient $(p<.05)$. Our findings are similar to studies $[7,9-10]$. It was determined that the burden mean scores of caregivers who did not receive help from others throughout the care process and who were obliged to provide care to another person were found to be higher [7, 9]. In our study, a statistically significant correlation was found between the presence of another person in the caregiving process and the care burden mean score. The care burden mean score of the caregivers who provided care to patients with metastases was found to be significantly higher than that of the caregivers with patients with no metastases and the finding is in line with the study of Kaynar\&Vural (2018) [5]. In our study, it was found that there was a weak and negative correlation between the perceived social support scores and caregiver burden scores $(p<.01)$ (Table 3$)$. In the advanced analysis, a highly significant correlation was found between the social support total scores and friend sub-dimension scores (Table 4). The reason for this is thought to be stemming from the fact that spouses, children and other family members support each other in case of an illness according to the traditional Turkish family structure. This finding is similar to that of the study conducted by Kaynar\& Vural (2018) [5]. According to the literature, the fact that caregivers have friends or families to discuss important things, getting help from them for home care activities as well as their provision of care to their patients and developing strategies collectively significantly reduce the care burden $[3,7-8]$. 
Table 4

The Effect of Independent Variables on the Zarit Caregiver Burden Scale Scores: Multiple Regression Analysis Results (n: 222)

\begin{tabular}{|c|c|c|c|c|c|c|c|c|c|}
\hline \multirow{2}{*}{$\begin{array}{l}\text { Independent Variables } \\
\text { Constant }\end{array}$} & \multirow{2}{*}{$\begin{array}{l}\text { B } \\
\\
6.52\end{array}$} & \multirow{2}{*}{$\begin{array}{l}\text { S. } \\
\text { Error } \\
6.44\end{array}$} & \multirow{3}{*}{$\begin{array}{l}\boldsymbol{\beta} \\
\\
.31\end{array}$} & \multirow{2}{*}{$\begin{array}{l}\mathbf{t} \\
1.012\end{array}$} & \multirow{2}{*}{$\begin{array}{l}\mathbf{p} \\
\\
.312\end{array}$} & \multicolumn{2}{|c|}{$\begin{array}{l}95 \% \\
\text { Confidence } \\
\text { Range for B }\end{array}$} & \multicolumn{2}{|c|}{$\begin{array}{l}\text { Collinearity } \\
\text { Statistics } \\
\text { Tolerance } \\
\text { VIF }\end{array}$} \\
\hline & & & & & & -6.17 & 19.21 & .975 & 1.026 \\
\hline $\begin{array}{l}\text { Home Care Practices } \\
\text { Questionnaire Form } \\
\text { Provision of Patient } \\
\text { Personal Care Sub- } \\
\text { Dimension }\end{array}$ & .77 & .15 & & 5.150 & .000 & .47 & 1.06 & & \\
\hline $\begin{array}{l}\text { Family Type } \\
\text { (1:large, 2: } \\
\text { nuclear, 3: } \\
\text { fragmented) }\end{array}$ & 4.46 & 1.76 & .16 & 2.537 & .012 & 1.00 & 7.93 & .903 & 1.107 \\
\hline Friend sub-dimension & -.31 & .13 & -.15 & -2.448 & .015 & -.57 & -.06 & .928 & 1.077 \\
\hline $\begin{array}{l}\text { Presence of another } \\
\text { person in }\end{array}$ & & & & & & & & & \\
\hline charge of care & 4.07 & 1.81 & .14 & 2.245 & .026 & .50 & 7.64 & .938 & 1.066 \\
\hline (1:yes, 2:no) & & & & & & & & & \\
\hline Metastases (1:no, 2:yes) & 4.06 & 1.85 & .14 & 2.190 & .030 & .41 & 7.71 & .933 & 1.072 \\
\hline $\begin{array}{l}\text { Responsibility of Providing } \\
\text { Care for another person }\end{array}$ & & & & & & & & & \\
\hline $\begin{array}{l}\text { Care for Others (1:no, } \\
\text { 2: yes) }\end{array}$ & 3.63 & 1.95 & .11 & 1.860 & .064 & -.22 & 7.48 & .944 & 1.059 \\
\hline
\end{tabular}

As a result; it was found that the home care practices of cancer caregivers and a lack of perceived social support increase the care burden. In this context, it is crucial to effectively identify the support needs of caregivers at home, to implement initiatives to reduce the care burden, to provide guidance on the social support they can receive as well as counseling services.

\section{Declarations}




\section{Author contribution:}

Funding was acquired by Özlem Uğur ( ÖU) and Tuba Ülgen (TÜ). TU and ÖU designed the study. All authors advised on data analysis and interpretation. ÖU wrote the first draft of the manuscript, which was reviewed and approved by all author.

\section{Availability of data and materials:}

Data are held securely by the research team and may be available upon reasonable request and with relevant approvals in place.

\section{Code availability:}

Not applicable

\section{Ethics Committee Process:}

All procedures performed in studies involving human participants were in accordance with the ethical standards of the institutional and/or national research committee and with the 1964 Helsinki declaration and its later amendments or comparable ethical standards. Written consent was obtained from the Ethics Committee of Dokuz Eylül University Research and Application Hospital, the department heads of the relevant clinics where the study was to be conducted.

\section{Consent to participate:}

All participants provided written, informed consent.

\section{Consent for publication:}

All participants provided consent for publication.

\section{Conflicts of interest:}

They have no financial interests.

\section{References}

1. Sert, H. A Common Problem of Oncology Patients? Relatives: Caregiver Burden. Türkiye Klinikleri Journal Of Internal Med. Nurs.-Special Topics 2015;1(2): 62-66. (Original work published in XXX[language name])

2. www. gco.iarc.fr > populations > 792-turkey-fact-sheets (Turkey Cancer Statistics 2017 )

3. Casado RP, Palomino-Moral PA, Martínez RM, Ramos-Morcillo AJ. Social support and subjective burden in caregivers of adults and older adults: A meta-analysis. PLoS One 2018, 13(1):1-18. doi: $10.1371 /$ journal.pone.0189874 
4. Hendrix CC, Bailey DE, Steinhauser KE, Olsen, et al. Effects Of Enhanced caregiver training Program On Cancer Caregiver's Self-Efficacy, Preparedness, And Psychological Well-Being. Support Care Cancer 2016; 24(1): 327-336. doi: 10.1007/s00520-015-2797-3.

5. Kaynar Ö, Vural F. Assessment of the Caregiver Burden of Caregivers of Colorectal Cancer Patients. Turk J Colorectal Dis. 2018; 28:164-171. doi: 10.4274/tjcd.26121.

6. Hasson-Ohayon I, Goldzweig G, Sela-Oren T, et al. Attachment Style, Social Support And Finding Meaning Among Spouses Of Colorectal Cancer Patients: Gender Differences. Palliat. Support Care 2015; 13(3):527-35. doi: 10.1017/S1478951513000242.

7. Sun X, Ge J, Meng H, et al. The Influence of Social Support and Care Burden on Depression among Caregivers of Patients with Severe Mental Illness in Rural Areas of Sichuan, China. Int J Environ Res Public Health 2019; 16(11): 1961. doi: 10.3390/ijerph16111961

8. Mohamed NE, Shah QN, Kata HE, et al. Dealing With the Unthinkable: Bladder and Colorectal Cancer Patients' and Informal Caregivers' Unmet Needs and Challenges in Life After Ostomies. Semin Oncol Nurs. 2021; 37(1):151111, doi: 10.1016/j.soncn.2020.

9. Doris $Y$, Leung P, Helen Y, et al. Source of Social Support and Caregiving Self-Efficacy on Caregiver Burden and Patient's Quality of Life: A Path Analysis on Patients with Palliative Care Needs and Their Caregivers. Int J Environ Res Public Health 2020; 17(15), 5457. https://doi.org/10.3390/ijerph17155457.

10. Ahn S, Romo RD, Campbell CL. A systematic review of interventions for family caregivers who care for patients with advanced cancer at home. Patient Educ Couns. 2020;103(8):1518-1530. doi: 10.1016/j.pec.2020.03.012.

11. Greer JA, Applebaum AJ, Jacobsen JC, et al. Understanding and Addressing the Role of Coping in Palliative Care for Patients With Advanced Cancer. J Clin Oncol. 2020; 38(9):915-925. doi: 10.1200/JC0.19.00013.

12. Halpern MT, Fiero MH, Bell M.L. Of Caregiver Activities And Social Supports On Multidimensional Caregiver burden: analyses from nationally-representative surveys of cancer patients and their caregivers. Qual Life Res. 2017; 26(6):1587-1595. doi: 10.1007/s11136-017-1505-9.

13. Wolff JL, Spillman BC, Freedman VA, Kasper JD. National Profile Of Family And Unpaid Caregivers Who Assist Older Adults With Health Care Activities. Internal Med. 2016;176(3):372-9. doi: 10.1001/jamainternmed.2015.7664.

14. Miller KD, Siegel RL, Lin CC, et al. Cancer Treatment And Survivorship Statistics, 2016. CA Cancer J Clin. 2016; 66(4):271-89. doi: 10.3322/caac.21349.

15. Zarit SH, Reever KE, Back-Peterson J. Relatives of the impaired elderly: correlates of feelings of burden. The Gerontologist 1980; 20, 649-655.

16. İnci, H. Adaptation, validity and reliability of care burden scale to Turkish. Master Thesis, Pamukkale University, Institute of Health Sciences 2006; Denizli, Turkey. (Original work published in Turkish)

17. Eker D, Arkar H, Yaldız H. Factor Structure, Validity And Reliability Of The Revised Form Of The Multidimensional Perceived Social Support Scale. Turkish Journal of Psych. 2011; 12(1):17-25. 
18. Karnofsky DA, Burchenal JH. "The Clinical Evaluation of Chemotherapeutic Agents in Cancer." In: MacLeod CM (Ed), Evaluation of Chemotherapeutic Agents. Columbia Univ Press. 1949; Page 196.

19. Dionne-Odom JN, Hull JG, Martin MY,et al. Associations Between Advanced Cancer Patients' Survival And Family Caregiver Presence And Burden. Cancer med. 2016; 5(5):853-862, doi: 10.1002/cam4.653.

20. Selçuk K, Avcı D. Care Burden and Affecting Factors in Caregivers of the Elderly with Chronic Disease. SDU Journal of Health Science Institute 2016; 7(1):1-9. (Original work published in Turkish)

21. Chua CK, Wu JT, Wong YY, et al. Caregiving And Its Resulting Effects The Care Study To Evaluate The Effects Of Caregiving On Caregivers Of Patients With Advanced Cancer in Singapore Cancers. Cancers. 2016,15;8(11). dol: 10.3390/cancers8110105 